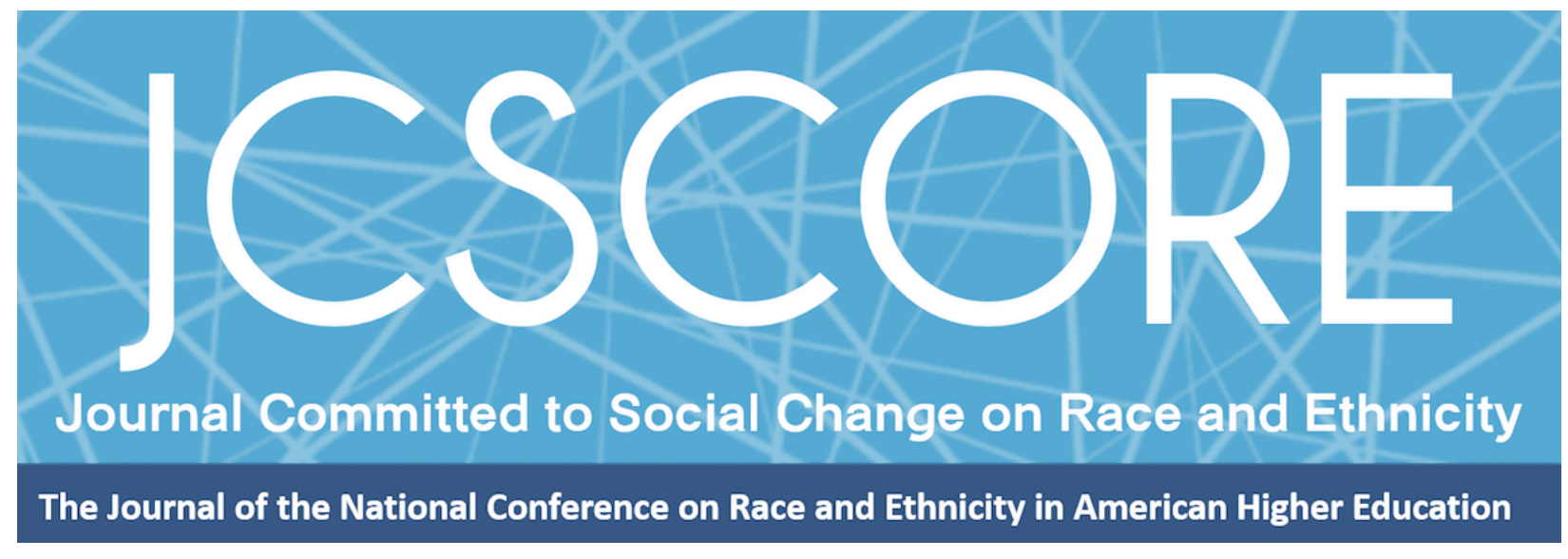

\title{
EXPLORING THE RELATIONSHIP BETWEEN CAMPUS CLIMATE AND MINORITY STRESS IN AFRICAN AMERICAN COLLEGE STUDENTS
}

\author{
Isaac Clark \\ Grand Valley State University \\ Donald Mitchell, Jr. \\ Bellarmine University
}

Journal Committed to Social Change on Race and Ethnicity

Volume 4 , Issue 1 | 2018

Copyright ( 2018 Board of Regents of The University of Oklahoma on behalf of the Southwest Center for Human Relations Studies.

Permission of the Publisher is required for resale or distribution and for all derivative works, including compilations and translations. Quoting small sections of text is allowed as long as there is appropriate attribution. 


\title{
Exploring the Relationship Between Campus Climate and Minority Stress in African American College Students
}

\author{
Isaac Clark \\ Grand Valley State University \\ Donald Mitchell, Jr. \\ Bellarmine University
}

\begin{abstract}
During recent decades, there has been a growth in research exploring the social experiences of African American students attending institutions of higher education. Research that examines minority stress suggests that students of color experience cognitive stressors specific to their racial identity or status as minorities on campus. Many studies have expanded on this knowledge in terms of academic achievement, retention, and adjustment to campus during the first year. The present study explored the concept of minority stress in relation to campus climate and the mental health of African American college students. The participants in this study consisted of eight college students from a predominantly White Midwestern university who identified as African American. Utilizing one-on-one interviews, the students discussed their experiences on campus, their perceptions of campus climate, the stress they experienced as students of color, and how these aspects may have contributed to symptoms of depression and anxiety. Information shared by the students indicated that campus climate and minority stress are closely associated with one another, especially when considering the racial status of the students. While students described feeling stress, discomfort, and burden due to campus climate and minority stress, the investigators were unable to determine if the symptoms described were, in fact, due to anxiety or depression.
\end{abstract}

For many, college serves as an avenue for academic growth, intellectual development, and vast social discovery. Because academic institutions are developmental spaces where millions of students live, learn, and work, they are also where students experience the social determinants of health during their collegiate careers. Defined as the conditions in which people live, work, and age, the social determinants of health have a direct impact on student health within the university (Office of Disease Prevention and Health Promotion [ODPHP], 2016). While not 
specifically stating that campus climate is a social determinant of health, Rankin and Reason (2005) noted that campus climate is a reflection of the actual or perceived attitudes, behaviors, and standards throughout a campus. Findings indicating that students of color are more likely to perceive predominantly White institutions (PWIs) of higher learning as hostile, uncomfortable, and unwelcoming have shown that campus climate may have a negative effect on students of color when considered as a social determinant of health.

Negative experiences and perceptions regarding campus climate on predominantly White campuses are more likely to occur for students of color (Rankin \& Reason, 2005). In comparison to White students, the added stress due to campus climate can be significantly worse for African American students who face stressors due specifically to their minority ${ }^{1}$ status (Green, Watkins, Guidry, Goodson, \& Stanley, 2007). In addition to the cognitive and subjective aspects of minority stress, related research has discussed topics such as stereotype threat. Steele (2003) described stereotype threat as situations where "individuals from stigmatized social categories are exposed as a result of their social, often a minority, position" (p. 253). An example of such exposure is having to deal with the confirmation or negation of a negative stereotype about oneself or one's group. Considering research highlighting the prevalence of mental health issues on college campuses, the additional stress faced by students of color may increase their risk of chronic stress, anxiety, and depression (National Institute of Mental Health [NIMH], 2016).

\footnotetext{
1 While we typically would not use the term minority in our work, but rather minoritized to highlight race and racism as social constructions (Harper, 2012), we sometimes used the term minority to align with previous literature, particularly literature related to minority stress.
} 
Journal Committed to Social Change on Race and Ethnicity | 2018

Statistics collected from the American College Health Association's National College Health Assessment Survey (ACHA-NCHA II) indicated that during the Fall 2015 semester—for undergraduate students overall—28\% reported experiencing overwhelming anxiety, $20 \%$ reported feelings of hopelessness, $22 \%$ expressed that stress negatively affected their grades, $17 \%$ expressed that anxiety negatively affected their grades, $13 \%$ expressed that depression negatively affected their grades, and $42 \%$ claimed that their university did not provide information regarding anxiety and depression. However, without stratification for race in these ACHA-NCHA II results, there is no specificity regarding the most prevalent types of mental illness affecting African American students, nor the extent to which they are affected. This study expands on the current knowledge base regarding minority stress and campus climate, and to explore if there might be a relationship of these factors to the mental health of African American students.

\section{Literature Review}

Social determinants of health can be defined as conditions in the social and physical environments in which people are born, live, work, and age (ODPHP, 2016). The majority of health determinants derive from experiences in physical and social environments, specifically from factors such as the availability or awareness of health resources; levels of physical activity and education; and eating, sleeping, and substance use habits (Sederer, 2016). Studies have found social determinants of health to be linked to chronic physical health outcomes such as diabetes, cardiovascular disease, and hypertension in addition to psychological symptoms, such as stress, depression, and anxiety (Graham, 2009; Sederer, 2016). While these studies made 
such conclusions based on findings within the general public, there is a lack of research regarding the social determinants of health as they relate to college campuses, specifically. Regarding the current study, the social determinants of health may be highlighted by descriptions of emotional, mental, and physical responses produced by physical and social interactions within the college environment. Considering research by Gusa (2010), students who are racial minorities attending predominantly White college environments are more likely to perceive them as uncomfortable and hostile. Because the college campus is a place where students live, work, and age, potentially for a number of years, expanding on the current literature regarding social determinants of health within campuses may be helpful toward making PWI environments more positive for future generations of minority students.

In 2014, 17.3 million undergraduate students were enrolled to attend universities across the nation (National Center for Education Statistics [NCES], 2015). Collectively, racial minority students accounted for less than $50 \%$ of the undergraduate population and, more specifically, African American students accounted for $12 \%$ of the undergraduate population. Research exploring psychological and social experiences of racial minority students indicated them feeling underrepresented, as well as out of place and unwelcomed within their higher education settings (Greer \& Brown, 2011; Housee, 2011). These perceptions of poor fit within the college environment can increase overall levels of experienced stress and can be reinforced by racially charged macroaggressions, strained relationships with professors, racial exclusion, marginalization, or challenges of racial authenticity (Greer \& Brown, 2011; Museus, Sariñana Lambe, Yee, \& Robinson, 2016; Wei et al., 2010). In addition, these 
perceptions have been shown to be closely related to minority student retention, especially within PWIs (Haring, 1999). While the enrollment rate of racial minority undergraduate students has grown by roughly six million since 1979 , minority students are still likely to enter university settings that are nearly racially homogenous, and endure increased risks of stress and adverse psychological symptoms during their collegiate experience (Greer \& Brown, 2011; Housee, 2011; NCES, 2015b). As interest in the social determinants of health has grown over the years, the concept has been added to Healthy People 2020's list of topics, with the objective of creating positive social and physical environments that promote good health for all (ODPHP, 2016). Because minority students have reported discomfort and feelings of being out of place or unwelcome in recent research, exploring the potential sources of their negative experiences may help reach Healthy People 2020's objective. Some specific factors found within current literature that may help to clarify the deficit in minority student comfort include minority stress and campus climate.

\section{Minority Stress}

Minority stress is described by Salami and Walker (2010) as an experience related to identification with a group that has historically been the target of discrimination. Wei and colleagues (2010) describe that racial minority students may experience minority stress within predominantly White campuses by directly experiencing racism or discrimination, having conflicts with cultural or social identities, as well as having difficulties making meaningful connections with White students and professors. To further highlight minority stress within PWI environments, Wei and colleagues (2010) reported that students can experience conflict within their identifying 
cultural group by being perceived as "acting White" (p. 412) by their peers. Similarly, when exploring the African American student experience, specific stressors among them include not wanting to be perceived as "acting too Black" by their White peers or professors, in addition to not wanting to be perceived as "acting too White" by other African Americans in the environment (Green et al., 2007, p.111). Green and colleagues (2007) described that these concerns were frequent sources of stress for the students and had one student question the actual meaning of what it is to be or act Black by emphasizing that the meaning is connected to historical and current stereotypes of Black people.

In describing minority stress, Meyer (2013) stated that individuals from stigmatized social categories can be "exposed because of their social, often a minority, position" (p. 675) and that social stress can have a strong impact on members of marginalized groups. The exposure discussed by Meyer (2013), for example, can be related to minority students either conforming or failing to confirm a racial stereotype belonging to their identifying cultural group, or as Steele (2003) described, "the threat of being viewed through a lens of a negative stereotype, or the fear of doing something to confirm a negative stereotype" (p. 253). With a multitude of negative stereotypes given to the African American race, stereotype threat may be a frequent stressor for African American students attending PWIs, and it can affect them socially as well as academically (Steele, 2003). While exploring the academic achievement of African American students was not the goal of the present study, it is important to note that stereotype threat has been widely researched as a negative factor on minority student performance (Johnson-Ahorlu, 2013). As the literature suggests, the stress solely 
associated with a student's minority status can have an affect on other generally stressful occurrences such as test taking, difficult homework, group assignments, and help-seeking practices (Greer \& Brown, 2011; Hurst, Baranik, \& Daniel, 2013). Such findings further differentiate the stress levels endured by minority students attending PWls in comparison to White students. In fact, Steele (2003) described that high levels of perceived stereotype threat during testing led to significantly lower standardized test scores for African American students in comparison to White students. While the effects of stereotype threat may not be overtly or physically noticeable, it may result in excelling academically or negative consequences such as students refraining from being social with others, deciding not to participate in class discussion, or neglecting to seek help when needed (Hurst et al., 2013; Johnson-Ahorlu, 2013).

\section{Campus Climate}

Early research about campus climate explained that it could be defined as the actual or perceived quality of interpersonal interactions on campus (Hurtado, 1992). Further research described campus climate in more detail, noting that it consists of the attitudes, behaviors, and standards of students, faculty, and staff members regarding the level of respect for individual needs, abilities, and potential (Rankin \& Reason, 2005). These definitions clarify that campus climate can be based on subjective perceptions of social interactions as well as concrete interactions that have been experienced across groups or individuals. When considering the racial demographic of PWIs, it is likely that in addition to the student body, the school's faculty, staff, and administration is also predominantly White. The National Center for Education Statistics (NCES, 2015a) has noted White faculty in academia outnumber 
Journal Committed to Social Change on Race and Ethnicity | 2018

faculty members of all other races by more than 400,000 persons. Gusa (2010) suggests that White institutional presence may be at the root of negative social interactions experienced by students of color, by describing that Whiteness is regarded as normative in such environments and that students of other races are often expected to conform.

Studies have found that it is not unusual for minority students to feel unwelcome in class, in assigned group projects, and during meetings with professors (Gusa, 2010; Minikel-Lacocque, 2013; Reid \& Radhakrishnan, 2003). Contrarily, for members of the majority population, the negative aspects of campus climate are less apparent and may go widely unnoticed. Studies have found that, in comparison to students of color, White students attending PWIs typically viewed campuses as welcoming, friendly, and respectful (Rankin \& Reason, 2005; Reid \& Radhakrishnan, 2003). According to research, factors such as ingroup-outgroup bias can affect the way that people are treated by those who are or are not members of the same cultural or social group (Dovidio, Gaertner, Yolanda, \& Snider, 2001). Specifically, research describes that people can either be rewarded or denigrated based on their affiliation to a certain group (Dovidio et al., 2001; Ufkes, Otten, Karen, \& Giebels, 2012). While this study did not seek to determine whether African American students are denigrated due to their racial status and presence on predominantly White campuses, ingroup-outgroup bias within institutions may be associated with how they are treated or perceive themselves to be treated. Gusa (2010) noted that while collegiate institutions may not be explicitly biased or racist, certain policies, perspectives, and curricula have been historically designed to primarily suit the needs of White students. 


\section{Significance of Stress Accumulation}

Considering that African American students attending PWIs are prone to experiencing stress due to the mental and physical requirements of college in addition to stress related to their minority status, the literature suggests that they experience more stress than White students. The accumulation of stress over time can result in adverse health effects and has been found to be related to chronic physical ailments such as hypertension and diabetes (NIMH, 2016). In terms of mental health, the NIMH (2016) has explained that cognitive symptoms of stress are related to depression and anxiety. With symptoms including hopelessness, difficulty concentrating, difficulty sleeping, sadness, worrying, and irritable mood, these psychological symptoms can be detrimental to the daily functioning, intellectual development, and overall academic success of college students. Single experiences of acute stress do not cause these symptoms to develop in an instant. Instead, they are more likely to develop when people experience chronic stress from the accumulation of stressful experiences over time (Cohen, Janicki-Deverts, \& Miller, 2007; McEwen, 2004).

\section{Rationale for the Current Study}

This study was developed with the following research questions in mind: How do campus climate and minority stress relate to one another, and do they contribute to symptoms of anxiety and depression in African American students? As the rate of firstyear African American college students entering academia increases (NCES, 2015b), this question continues to grow in significance. The purpose of this study was to expand upon current research regarding minority stress and campus climate by identifying (a) stressors that African American students experience in the campus 
environment, (b) the extent to which they are affected by the stressors, (c) how African American students perceive campus climate, and (d) how minority stress and campus climate may contribute to symptoms of anxiety and depression.

\section{Methods}

This study utilized a phenomenological approach to explore the stressful experiences of African American college students and how they might relate to campus climate and symptoms of anxiety and depression. Phenomenology can be described as a self-critical methodology that is based on exploring lived experiences as they have been perceived by the human consciousness (Reeder, 2009). Specifically, this approach focuses on exploring the concepts, events, and lived experiences of study participants (Saldana, 2011). Utilizing this approach allows researchers to capture the essence and essentials of each participant's experience and produce intimate findings that increase awareness and generate deep understandings for readers (Saldana, 2011). Because this study aimed to explore relationships that do not have much representation in the current base of knowledge, unique and rich information from each participant was essential to expand on what is currently known about minority stress, campus climate, and mental health.

\section{Participants and Setting}

A purposeful sample of African American college students attending a Midwestern university was invited to participate in the study, meaning that the population of students was selected based on their potential to provide information-rich descriptions related to the phenomenon of interest (Palinkas et al., 2015). In total, 10 students who attended the university and identified as Black or African American were 
randomly selected from two cultural student organizations to be interviewed. After losing communication with two potential participants, eight of the 10 selected participants completed the interview process. The participating students included three females and five males. The group included three seniors, one post-baccalaureate student, two juniors, and two sophomores. All participating students received university-themed water bottles and the opportunity to win one of three $\$ 25$ gift cards following the completion of data collection.

At the institution where the study occurred, African American students are classified as minority students, representing less than $10 \%$ of all students attending the university. Brown and Dancy (2010) indicated that when more than $50 \%$ of student enrollment consists of White students, a university is to be classified as predominantly White. Because the student body of the university in this study includes more than $75 \%$ White students, it is classified as a PWI. This particular setting was desired because it would tend to draw out findings from students of color if they were having negative and uncomfortable experiences on a PWI campus.

\section{Qualitative Data Collection and Analysis}

With approval from the university's Institutional Review Board, a qualitative semistructured interview guide was developed to collect data for this study. Students were interviewed during the academic year and were asked 18 questions structured to collect information regarding their perceptions of campus climate, uncomfortable social situations that they had experienced, minority stress, and symptoms of anxiety and depression. For example, interview questions included the following: Tell me about a time when you have made a conscious effort to avoid confirming a negative stereotype 
about yourself and how did it make you feel? What do you find most stressful as a student of color? Have social interactions contributed to feelings of hopelessness? This semi-structured protocol allowed the interviewer to use probing questions to gain rich, detailed information. Interviews were conducted, and each interview lasted between approximately 45 minutes. With the consent of the participants, the interviews were audio recorded for transcription purposes.

Once the interviews were completed, all interviews were transcribed. Then, all textual data was reviewed and compared with the audio recordings to check the accuracy of the data. Next, the data was analyzed by using open, axial, and selective coding. Respectively, these methods involved identifying or tagging units of data that were relevant to the study, relating identified and tagged codes to one another to develop concepts, and selecting core themes based on the concepts (Merriam, 2009).

\section{Findings}

To protect participant identity, each student was assigned a pseudonym. Table 1 provides the pseudonym and demographic information for each student involved in the study.

Table 1. Interview Participants

\begin{tabular}{|l|l|l|l|}
\hline Pseudonym & Age & Sex & Academic Classification \\
\hline Marcus & 20 & Male & Sophomore \\
\hline Janelle & 22 & Female & Post-baccalaureate \\
\hline Brandon & 20 & Male & Junior \\
\hline Derek & 22 & Male & Senior \\
\hline Karen & 20 & Female & Senior \\
\hline Marcel & 20 & Male & Junior \\
\hline Taylor & 19 & Female & Sophomore \\
\hline Elijah & 21 & Male & Senior \\
\hline
\end{tabular}

Overall, the findings highlighted ways in which participants perceived and experienced the campus climate, the ways it made them feel uncomfortable, and their 
emotions and reactions to the campus climate. The results also highlighted how the students have experienced minority stress, including factors such as microaggressions and stereotype threat that contribute to minority stress. It is important to note that while the investigators sought to explore mental health symptoms, during the triangulation process they determined that the students did not provide adequate evidence that their experiences were coupled with symptoms of anxiety and depression. For example, when asked specifically about a symptom (e.g., hopelessness), students typically related it back to school-work or classes rather than campus climate or minority stress.

\section{Perceptions and Experiences of Campus Climate}

Most students who were interviewed stated that they felt their campus climate was not racially diverse. The students indicated that their race was a factor in how they felt they were being perceived and/or treated by others on campus. Specifically, they described how race, cultural norms, and assumptions of cultural norms were factors that affected the attitudes people may have had about them and their abilities or potential. Elijah described raising some eyebrows in class with a level of intelligence that, he felt, people would not expect based on his appearance. With the idea that his clothing options sometimes fit him into a racial stereotype, he felt as if people did not expect him to be as well-spoken or as intelligent as he is:

In class, I'm always well spoken, and I can tell that people [are] surprised sometimes, because sometimes I might come into class with my hat on backwards and some Jordan's. But when I come in on the first day, and they ask me something, and I give them [an] answer that they probably wouldn't even thought of from the smartest person in this class, they just be looking like, "Wow. He really knows some stuff." Yeah, I do.

Marcel was another student who experienced being perceived in a certain way based on his attire and, most importantly, his interactions were also related to race. He 
described that, as a Black male, he felt the need to dress professionally and has made the effort to incorporate business casual attire into his everyday wear. He expressed his frustrations with what some people had said regarding his clothing and what people categorize as Black or White characteristics:

Like what l'm wearing right now. People say like, that's not how most Black guys dress. Well you know, why am I not the representation of what a Black person is? You know what I mean? Why is it that when I show good characteristics, good character, and speak well, I'm representing White people? The struggle is hearing that, and when it's from my White friends saying, "Oh, it feels like you're not like really Black to me." Like what!? That just means you don't see my color, so you don't understand my struggle.

Marcus explained a situation in which his race led to assumptions being made about his upbringing and the abilities he may have:

Yeah, so it's just that people have all these [preconceptions] about you and where you come from. It was my first time meeting [White] people, they would always ask me like, "Oh yeah, you came from the hood, so like, you can say or do certain things," or "Aw, I bet you could rap, huh?" Although that might be the case sometimes, it still kinda sucks that people ask you about certain things like that.

These descriptions show that race can serve as an overarching factor that affects the climate of campus, i.e., the actual or perceived quality of interpersonal interactions on campus and the attitudes, behaviors, and standards of others regarding the level of respect for individual needs, abilities, and potential.

For many of the students, uncomfortable experiences were commonly coupled with their perceptions or experiences of campus climate. Taylor described how the attitudes she believed that people had about her would make the classroom setting uncomfortable. She highlighted that her discomfort in the classroom setting would sometimes cause her to react by not participating in discussion. Specifically, she 
explained that her discomfort stemmed from the feeling that, as an African American

student, other students expect her to behave a certain way. She went on to explain:

The most stressful thing as a student of color is just knowing that there are people in your class who are going to expect more out of you, whether it be dumb or intelligent. It's just the fact that, you know, the first thing that come out of your mouth in that class, you're judged on it no matter what. So, it's just knowing that alone will make me not wanna say anything in classes sometimes. It took me awhile to participate in classes and I think that is why, because I'm just like I already know.

Marcus described an uncomfortable experience that resulted from friends being curious about using a racially sensitive term. Unlike the behavioral reactions of Taylor, Marcus experienced an emotional reaction after thinking about the question he had been asked:

So there was a couple times where I was on campus just having conversations with some acquaintances, people... I guess I call friends sometimes. And uh, there [were] a couple times where they asked me if it was okay to say the $\mathrm{n}$ word, you know? And so, that made me a little bit uncomfortable because they don't realize the back story behind where that comes from. Like they just look at it as another term, and some people just look at it [as], "Oh, it's just something that people of color say." [But] it's like, "No, that's not comfortable to say." And I guess that's happened two or three times. When it first happened, I was like, shocked. I wasn't expecting it, so I didn't really react to it. But once I started to think about it and let it sit on my mind, [I] got angry about it, 'cause I'm like, "How would you feel if I asked you if I can call you a word that offends who you are and your history?" It kind of made me upset that somebody would ask me something like that.

Janelle and Taylor both described uncomfortable experiences based on the actions of others on campus. Both of them discussed how they would create an open seat for students to sit when the university's bus became full, but for some reason students did not sit next to them. While Janelle mentioned that it made her uncomfortable, Taylor shared this information while describing some of the microaggressions that she has faced. Janelle explained:

I feel uncomfortable when I get on the bus and people would rather stand up than sit next to me. ... The seat's open too, and like l'll hold my backpack in my lap so 
the seat's very available, and they just would rather not, and it's so uncomfortable and so frustrating.

Taylor shared:

I've been working in the same office and with the same people every day for the past two years, pretty much, and whenever I go into my office there are three people in there, for whatever reason, will never say hello to the entire group of [Black] people that's there. ... and it genuinely irritates my soul. Or if I'm on the bus and everybody's standing up, but there is an open seat right next to me, but nobody sits down next to me. That's a micro-aggression. That is the worst one 'cause that happens every time I get on the bus and I don't get it 'cause I'll sit down next to you. I don't care. Like, you're a person, but people, they don't do it and I'm like, "Am I scary?"

These findings highlight the ways in which campus climate can be uncomfortable for African American students and how race is a key aspect of how African American students feel they are perceived and/or treated by others on campus. Participants in this study were able to link their race to experiences of campus climate and minority stress.

\section{Minority Stress}

Participants of this study expressed that minority stress was experienced. One of the commonalities among students was the awareness of being the only African American in an area or classroom. Some of the students had uncomfortable experiences in these situations while others used their minority stress as motivation to achieve goals. In addition, participants of this study would experience discomfort due to microaggressions and stereotype threat. In referring to being the only student of color in most of her social work classes, Karen, a social work major, described how classroom settings could become uncomfortable during racial discussions:

Racial discussions. I hate them. I wish it would be, like, put on the syllabus so I'd know they were gonna talk about it, so I wouldn't go to class. In all these classes, especially the social work ones, we're talking about injustice and a lot of 
the injustice in the U.S. Blacks are a big part of that, so it's like, I'm constantly hearing people talk about how people like me are getting treated like shit, and it's been like that, and that's the way it's set up. And then it's like, you're hearing this from White people and it's like. ... That's too much. I can't stand it.

Marcus described how he feels the pressure to work harder when he realizes that he is the only minority student: "Back to this stress part, so me going to an environment where like, [l'm] the only minority. You know, it kind of hits [me] like man, I gotta work hard like, a lot harder."

Brandon, an international student from Africa, described the burden he feels when he is the only minority student in class: "I feel like I'm representing African American, and Africans, and all people of color and then it's this overwhelming burden sometimes. You know?"

Derek explained the burden of representing his culture and how he uses his minority stress to his advantage in terms of learning:

Specifically, because when you're the only one, you kind of feel like there's a burden of your whole culture on your shoulders, because if you do one bad thing, everyone in class is looking like, "Oh, all Black people are like that," in a way. So it kind of motivates me to just work hard and try and beat that stereotype or just pretty much just work hard, just do my best.

While not specifically mentioning the demographics of her classroom, Janelle highlighted that she would sometimes struggle with the power dynamic between herself and her White professors:

Having White professors and being a Black female student, it's a lot of contrast there because of the whole White supremacy, male dominancy type of thing. And it's like I already got two odds against me, I'm Black and I'm female. So, it was like a constant battle of me showing my professor, "You might be my professor, but you're not superior to me."

The students interviewed at this university also experienced stereotype threat on the campus. They explained that they would feel the need to distance themselves from 
friends in public spaces, so they would not be classified into a negative category by other students. Marcus shared how he felt after describing situations in which he had to distance himself from friends in public:

I can remember [a] couple times where l've like, purposely not did certain things like not hanging out with a group of ... people or talking about certain things in public environments to kind of make it seem like I present myself, [or am] trying to present myself differently. And now that I'm thinking about it, kind of makes me like, feel ashamed sometimes.

Janelle described how she would do the same thing to uphold a positive image on campus:

I would always ... try to kind of be a little off to the side when I would be around my groups of friends if they started getting loud and stuff 'cause I didn't want to be associated with, "Oh my God, this girl wants to be a leader of this campus, but look at the people she hangs out with." [l'd] be like all right, let me just kind of slide to the left a little bit 'cause I don't want look like an ignorant Black person.

Brandon described that his desire to avoid racial stereotypes influenced him to keep his computer science major a secret:

I've had to hide the fact that I'm doing computer science because nobody expected me to be doing computer science. ... My manager at my work, first semester, asked me, "what major are you doing," and I said "computer science", very proud. That was one of the turning points of [when] I started just hiding the stereotype. She straight up told me, "Oh, so you're smart." It was my last day at that job. I just said, okay, I'll just let this slide and get out with a good relationship. And from there on, I've been very aware of who I tell what my major is because they might start to bring up the stereotypes.

Some of the microaggressions that students described were associated with standards that people held on campus regarding what characterizes White or Black. Karen explained an experience similar to when Marcel received feedback about his clothing.

She said:

At my job, one of my managers, she was like-because I was changing to go do something or whatever-"You don't dress like, you know, normal Black girls." And I was like, "What does that mean?" And she was like, "Yeah, you just. They 
just dress different. I like it." What do you think Black girls dress like? That was really ignorant to me and frustrating.

Elijah described a time when he experienced microaggressions in the classroom:

I remember one day. I think this was my first semester here I believe. Yeah, it was a sociology class I had and the professor, he asked, "What does it mean to be White?" And he asked the class: White professor, predominantly White class. But it was actually a couple [Black] students; I think it was about five of us. But, you know, people just [were] saying some ignorant stuff, talking about, well, like, not sagging.

In describing what he found most stressful about being a student of color, Elijah mentioned the struggle with trying to connect with people of the campus' majority population. In his description, he mentioned code-switching, which indicated that he would sometimes speak or behave differently around people not belonging to his cultural group. He described it this way:

How do I phrase this? It's really trying to connect with the general, you know, population on campus because of course I can [code] switch easily. I can jump into something and get it, but it [becomes] tiring at a point, like, [l'm] tired of having to compress myself to accommodate other people and all that. I'm tired of it, [and] it's just part of the problem.

These descriptions, in addition to earlier descriptions by Marcel and Taylor, showed that microaggressions can be perceived as or are actually related to the attitudes people have regarding race. In addition, the shared experiences showed that, even when statements are made out to be compliments, they can be rude or offensive to African American students based on their implications, i.e., what characteristics are generalized to Black or White people.

\section{Limitations}

Regarding the findings of this study, it is important to indicate its limitations. First, the sample of participants came from just two of the university's cultural 
organizations. While the students fit the phenomenon of interest, their experience may not be a reflection of the entire population since qualitative research is not intended to be generalizable. Second, the participants' willingness to participate in the study may have been based on their personal interests in the topic, which can potentially create bias. Third, during interviews the students had difficulty remembering certain events. This would be an example of recall bias, which has the potential to affect the richness and details of lived experiences. Fourth, there were fewer female participants than males involved in the study. Female participants highlighted unique experiences, and with less female representation, there was less to be analyzed from the female perspective. Finally, the method of data collection for the symptoms of anxiety and depression could have been improved. Questions were adapted from multiple-choice mental health questionnaires and asked using a one-on-one interview protocol. A mixed-methods approach might have been more efficient by allowing for experiences of mental health symptoms to be explored quantitatively. Ultimately, although these limitations exist, this study has the potential to add to the current base of knowledge.

\section{Discussion}

This study aimed to explore the possible relationships between campus climate, minority stress, and symptoms of anxiety and/or depression for African American college students attending a PWI in the Midwest. To collect data for this research, we used one-on-one interviews to gather information about the unique experiences and perceptions of African American students when it came to campus climate and minority stress. The findings suggest that racial status is a factor that can affect the perceptions and experiences of campus climate for African American students. In relation to their 
race, campus climate sometimes became uncomfortable for study participants, leading to reactions such as the desire to miss class, efforts to resist being associated with negative stereotypes, perceived conflicts between staff and students of the university, and emotions such as frustration, anger, and shame.

Some of the students indicated that they would be complimented by White staff and students for deviating from the ways that Black people normally behave and/or dress. Students also described that they would sometimes avoid being seen in public with a group of other African Americans to present themselves differently (e.g., when Janelle described not wanting to be perceived as an "ignorant Black person"). These findings support the findings of Green et al. (2007), who indicated that African American students would rather not be perceived as behaving "too Black" (p. 111). These findings suggest that African American students can sometimes be seen through stereotypical lenses and can be expected to present themselves in certain ways or behave in certain ways. As Karen described, she became frustrated when she was complimented for not dressing like Black girls typically do. In research by Green and colleagues (2007), one student mentioned that the ideas of what it is to be Black are rooted in stereotypes that were generated throughout history. These stereotypes consequentially cause stress for students when they are called out on them or when they feel that they are in the process of confirming one.

In addition, the findings of this study indicate that the apparent racial status of these students is something resonating within their minds as well as in the minds of others on their campus. Positive reinforcement of characteristics that some White students and staff believe are acceptable may be contributing to the stereotype threat 
experienced by the students. Findings indicate that the students constantly check themselves as African Americans, especially based on the ways they present themselves in public. Elijah was the only student who mentioned his exhaustion with code-switching and actively accommodating others around campus. His comment on the topic showed that he feels the pressure to align himself with the dominant presence on campus by accommodating the campus climate instead of the campus being developed to accommodate him. These findings confirm research by Gusa (2010) describing that non-majority students in PWls are expected to conform to White traditions and standards on campus. While Elijah was the only student to discuss codeswitching and assimilation, other students also described feeling pressure from the campus climate to behave in specific ways within social environments. Actions such as avoiding participation in class discussions, avoiding conversations about academic interests, and attempts to avoid stereotypes were all described by the participating students.

Amplified racial representation also was something that the students experienced within their university and was something that they all described as stressful. While some students described the stress of being the only African American or racial minority within certain settings as a burden, other students indicated that it was motivating and has helped them academically. In their descriptions of how amplified racial representation can be motivational, students mentioned feeling that people would be expecting them to fail or that, if they did fail, their entire race would take a negative strike because of it. This further highlights how racial status is an aspect that can influence the perceptions and experiences of campus climate and how students believe 
they are being perceived and treated by others. For students who had achieved academic goals while being motivated by increased racial representation, each described feeling as if they were already being seen through a negative or stereotypical lens. This shows that even though all Black students may not be negatively impacted by stereotype threat, the potential stereotypes that they may be put in are things that they worry about frequently.

These findings support research by Gusa (2010), who described how the White institutional presence of a campus can contribute to environments that are perceived as hostile and uncomfortable for racial minority students. As previously discussed, students of this study mentioned being complimented on characteristics that were described as deviating from the "Black norm," feeling the need to avoid being seen with friends of their racial group so they could be seen by the campus majority in a positive light, and constantly needing to check their behaviors, actions, and interests because of their racial status and the campus climate. These explanations suggest that the campus climate of their university adds a sense of pressure on them to conform to majority or White standards. As Gusa (2010) described, universities may not aim to be racially biased, but the policies and perspectives within the university may be rooted and geared toward White students, thus reinforcing White traditions and standards. Thus, campuses may be promoting monoculturalistic values and creating uncomfortable environments without meaning to do so (Gusa, 2010). For example, when White staff members compliment Black students for deviating from the "Black norm," they are also telling those students that the way they naturally compose themselves is not acceptable. 
Although researchers were not able to find concrete evidence that the stress and other symptoms were results of anxiety or depression in African American students, stress was a factor that was prevalent throughout all students. Students reported having emotional as well as physical responses to their environment whether it was anger, frustration, deciding not to go to class during racial discussions, or dressing a certain way not to be perceived as a typical Black person. These students described facing the reality of their race as well as the questions, misconceptions, unwelcoming attitudes, and stereotypes that people may have regarding their racial status. All of which are stressors that they have to endure very frequently in their environment. Considering the effects of accumulated stress over time, it is wise to consider what can be done to minimize stressful situations for students of color.

Wei and colleagues (2010) described how bicultural competence among minority students can help reduce the effects of minority stress and depressive symptoms. Specifically, Wei et al. discussed that when students know more about their cultural history and the history of others in their institution, they are less likely to experience depressive symptoms that are associated with minority stress. While improving bicultural competence may be a useful strategy, it is apparent that some campus climates are not as culturally competent as they could be regarding the numerous cultures that exist within their student body. Increasing cultural competence across entire campuses may be more effective in terms of making campus climates more welcoming, comfortable, and supportive for all students of color. 


\section{Future Research}

With the current findings indicating an association between campus climate and minority stress, a mixed methods version of this study would be beneficial in determining whether these results are generalizable. If found to be generalizable, exploring the influence of African American cultural competency training may be an important step in helping predominantly White campuses be more inclusive and welcoming for African American college students. In addition, we recommend that future studies explore links to mental health symptoms by studying a population of students who have already been diagnosed with anxiety or depression. This will help to identify factors of minority stress and campus climate that affect those who have diagnoses and allow further questions to develop about how the same factors may contribute to psychological mood symptoms of students without diagnoses. Finally, because these participants did not indicate experiencing psychological symptoms due to campus climate or minority stress, exploring coping mechanisms of African American students may provide further insight into their experiences.

\section{Conclusion}

The findings of this study suggest that campus climate and minority stress are closely associated. Racial status was found to be a factor that can affect the perceptions and experiences of campus climate for African American students and was also a key contributor to minority stress at the university. In relation to their race, campus climate sometimes became uncomfortable for study participants, leading to reactions such as the desire to miss class, efforts to resist being associated with negative stereotypes, perceived conflicts between staff and students of the university, 
Journal Committed to Social Change on Race and Ethnicity | 2018

and emotions such as frustration, anger, and shame. Given that educational

institutions' missions are to educate all students, when they fall short as described by

these participants, they must be held accountable. In the end, this accountability will be beneficial for the students, the institution, and society. 


\section{References}

American College Health Association-National College Health Assessment Survey. (2016). Undergraduate reference group data report-Fall 2015. Retrieved from http://www.acha-ncha.org/reports_ACHA-NCHAllc.html

Brown II, C. M., \& Dancy II, T. E. (2010). Predominantly White institutions. In K. Lomotey (Ed.), Encyclopedia of African American education (pp. 524-526). Thousand Oaks, CA: Sage.

Cohen, S., Janicki-Deverts D., \& Miller G. E. (2007). Psychological stress and disease. Journal of the American Medical Association, 298(14), 1685-1687.

Dovidio, J. F., Gaertner, S. L., Yolanda, F. N., \& Snider, K. (2001). Racial, ethnic, and cultural differences in responding to distinctiveness and discrimination on campus: Stigma and common group identity. Journal of Social Issues, 57(1), 167-188.

Graham, H. (2009). Health inequalities, social determinants and public health policy. Policy \& Politics, 37(4), 463-479.

Green, B. L., Watkins, D. C., Guidry, J. J., Goodson, P., \& Stanley, C. A. (2007). Using focus groups to explore the stressful life events of Black college men. Journal of College Student Development, 48(1), 105-118.

Greer, T. M., \& Brown, P. (2011). Minority status stress and coping processes among African American college students. Journal of Diversity in Higher Education, 4(1), 26-38.

Gusa, D. L. (2010). White institutional presence: The impact of whiteness on campus climate. Harvard Educational Review, 80(4), 464-490.

Haring, M. J. (1999). The case for a conceptual base for minority mentoring programs. Peabody Journal of Education, 74(2), 5-14.

Harper, S. R. (2012). Race without racism: How higher education researchers minimize racist institutional norms. Review of Higher Education, 36(1), 9-29.

Housee, S. (2011). What difference does 'difference' make? A discussion with ethnic minority students about their learning experience in higher education. Learning and Teaching, 4(1), 70-91.

Hurst, C. S., Baranik, L. E., \& Daniel, F. (2013). College student stressors: A review of the qualitative research. Stress \& Health: Journal of the International Society for the Investigation of Stress, 29(4), 275-285.

Hurtado, S. (1992). The campus racial climate: Contexts of conflict. Journal of Higher Education, 63(5), 539-569.

Johnson-Ahorlu, R. (2013). "Our biggest challenge is stereotypes": Understanding stereotype threat and the academic experiences of African American undergraduates. Journal of Negro Education, 82(4), 382-392.

McEwen, B. (2004). Protection and damage from acute and chronic stress: Allostasis and allostatic overload and relevance to the pathophysiology of psychiatric disorders. Biobehavioral Stress Response: Protective and Damaging Effects, 1032, 1-7.

Merriam, S. B. (2009). Qualitative research: A guide to design and implementation. San Francisco, CA: Jossey-Bass.

Meyer, I. H. (2013). Prejudice, social stress, and mental health in lesbian, gay, and bisexual populations: Conceptual issues and research evidence. Psychology of Sexual Orientation and Gender Diversity, 1, 3-26. 
Minikel-Lacocque, J. (2013). Racism, college, and the power of words: Racial microaggressions reconsidered. American Educational Research Journal, 50(3), 432-465.

Museus, S. D., Sariñana Lambe, S. A., Yee, A. L., \& Robinson, T. E. (2016). A qualitative analysis of multiracial students' experiences with prejudice and discrimination in college. Journal of College Student Development, 57(6), 680-697.

National Center for Education Statistics, Institute of Education Sciences. (2015a). Fulltime faculty in degree-granting postsecondary institutions, by race/ethnicity, sex, and academic rank: Fall 2011, fall 2013, and fall 2015. Retrieved from https://nces.ed.gov/programs/digest/d16/tables/dt16_315.20.asp?current=yes

National Center for Education Statistics, Institute of Education Sciences. (2015b). Total fall enrollment in degree-granting postsecondary institutions, by level of enrollment, sex, attendance status, and race/ethnicity of student: Selected years, 1976 through 2014. Retrieved from http://nces.ed.gov/programs/digest/d15/tables/dt15_306.10.asp?current=yes National Institute of Mental Health. (2016). Mental health information: Depression. Retrieved from https://www.nimh.nih.gov/health/topics/depression/index.shtml Office of Disease Prevention and Health Promotion. (2016). Social determinants of health. In Healthy People 2020. Retrieved from http://www.healthypeople.gov/

Palinkas, L. A., Horwitz, S. M., Green, C. A., Wisdom, J. P., Duan, N., \& Hoagwood, K. (2015). Purposeful sampling for qualitative data collection and analysis in mixed method implementation research. Administration and Policy in Mental Health, 42(5), 533-544. http://doi.org/10.1007/s10488-013-0528-y

Rankin, S. R., \& Reason, R. D. (2005). Differing perceptions: How students of color and white students perceive campus climate for underrepresented groups. Journal of College Student Development, 46(1), 43-61.

Reeder, H. P. (2009). Theory and practice of Husserl's phenomenology. Villejuif Cedex, FR: Zeta.

Reid, L. D., \& Radhakrishnan, P. (2003). Race matters: The relation between race and general campus climate. Cultural Diversity and Ethnic Minority Psychology, 9(3), 263-275.

Salami, T. K., \& Walker, R. L. (2014). Socioeconomic status and symptoms of depression and anxiety in African American college students: The mediating role of hopelessness. Journal of Black Psychology, 40(3), 275-290. doi:10.1177/0095798413486158

Saldaña, J. (2011). Fundamentals of qualitative research. New York, NY: Oxford University Press.

Sederer, L. (2016). The social determinants of mental health. Psychiatric Services, 67(2), 234-235.

Steele, C. (2003). Stereotype threat and African-American student achievement. In T. Perry, C. M. Steele \& A. G. Hilliard (Eds.), Young, gifted, and black: Promoting high achievement among African-American students (pp. 252-257). Boston, MA: Beacon.

Ufkes, E. G., Otten, S., van, K. I., \& Giebels, E. (2012). Neighborhood conflicts: The role of social categorization. International Journal of Conflict Management, 23(3), 290306. 
Journal Committed to Social Change on Race and Ethnicity | 2018

Wei, M., Liao, K., Chao, R., Mallinckrodt, B., Tsai, P., \& Botello-Zamarron, R. (2010). Minority stress, perceived bicultural competence, and depressive symptoms among ethnic minority college students. Journal of Counseling Psychology, 57(4), 411-422. 